\title{
A METODOLOGIA DE RESOLUÇÃO DE PROBLEMAS NO ENSINO DE CIÊNCIAS: AS CARACTERÍSTICAS DE UM PROBLEMA EFICAZ
}

\author{
DANIEL DAS CHAGAS DE AZEVEDO RIBEIRO * \\ https://orcid.org/0000-0002-2564-7164 \\ CAMILA GREFF PASSOS ${ }^{1 * *}$ \\ https://orcid.org/0000-0003-1110-9354
}

TANIA DENISE MISKINIS SALGADO ${ }^{* * *}$

https://orcid.org/0000-0001-6828-6672

RESUMO: Na literatura, encontramos algumas classificações para os enunciados dos problemas, mas existem escassas discussões sobre como elaborar bons problemas para serem utilizados com a metodologia de Resolução de Problemas. Nesse sentido, o objetivo do presente estudo é apresentar características fundamentais de um Problema Eficaz para o Ensino de Ciências. A partir das investigações desenvolvidas ao longo da última década, propomos que um Problema Eficaz deve contextualizar a temática à realidade do aluno, suscitar a reflexão crítica acerca do assunto abordado, motivar o estudante e tornar a proposição passível de ser pesquisada. Nossa intenção com este artigo é oferecer subsídios aos professores na elaboração e utilização de problemas investigativos em suas aulas.

Palavras-chave: Resolução de Problemas. Ensino de Ciências. Problema Eficaz.

\section{LA METODOLOGÍA DE LA RESOLUCIÓN DE PROBLEMAS EN LA ENSEÑANZA DE CIENCIA: LAS CARACTERÍSTICAS DE UN PROBLEMA EFICAZ}

RESUMEN: En la literatura hallamos algunas clasificaciones para los enunciados de los problemas, pero existen pocas discusiones acerca de cómo elaborar buenos problemas para que se utilicen con la metodología de Resolución de Problemas. En ese sentido, el objetivo de este estudio es presentar características fundamentales de un Problema Eficaz a la Enseñanza de Ciencias. A partir de

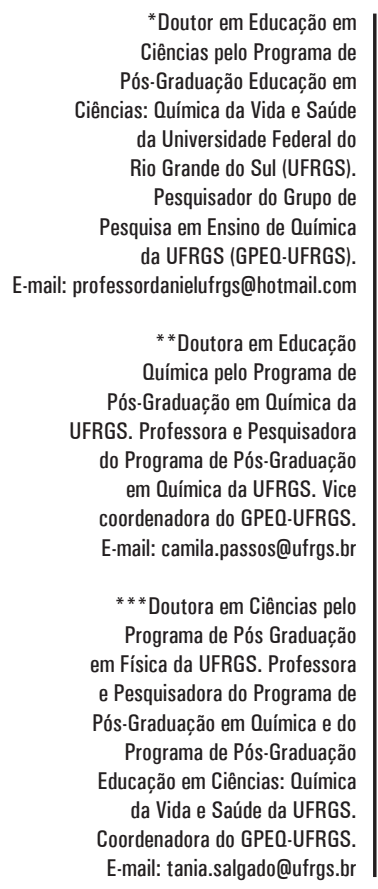

*Doutor em Educação em Pós-Graduação Educação em e Caúd da Universidade Federal do Rio Grande do Sul (UFRGS). squisa em Ensino de Química da UFRGS (GPEQ-UFRGS).

**Doutora em Educação Química pelo Programa de -Graduação em Química da FRGS. Professora e Pesquisadora Programa de Pós-Graduação em Química da UFRGS. Vice coordenadora do GPEQ-UFRGS. E-mail: camila.passos@ufrgs.b

outora em Ciências pelo e Pesquisadora do Programa de Pós-Graduação em Química e do Programa de Pós-Graduação Educação em Ciências: Química Coordenadora do GPEQ-UFRGS. E-mail: tania.salgado@ufrgs.br

I Universidade Federal do Rio Grande do Sul, Programa de Pós-Graduação Educação em Ciências: Química da Vida e Saúde, Porto Alegre. RS - Brasil. II Universidade Federal do Rio Grande do Sul, Programa de Pós-Graduação em Química, Porto Alegre. RS - Brasil. 
investigaciones desarrolladas a lo largo de la última década, proponemos que un Problema Eficaz debe contextualizar la temática en la realidad del alumno, suscitar la reflexión crítica acerca del asunto abordado, motivar el estudiante y tornar la proposición en objeto de investigación. Nuestra intención con este artículo es ofrecer auxilio a los profesores en la elaboración y utilización de los problemas investigativos en sus clases.

Palabras clave: Resolución de Problemas. Enseñanza de Ciencias. Problema Eficaz.

THE PROBLEM-SOLVING METHODOLOGY IN SCIENCE TEACHING: THE CHARACTERISTICS OF AN EFFECTIVE PROBLEM

ABSTRACT: In the literature, we find some classifications for the problems statements, but there are few discussions on how to elaborate good problems to be used based on the ProblemSolving methodology. In this sense, the aim of this study is to present the fundamental characteristics of an Effective Problem for Science Teaching. Based on the investigations carried out over the last decade, we propose that an Effective Problem should contextualize the theme to students' reality, raise critical reflection on the addressed subject, motivate the student and make the proposition susceptible to be researched. Our intention with this article is to offer subsides to teachers in the elaboration and use of investigative problems in their classes.

Keywords: Problem-Solving. Science Teaching. Effective Problem. 


\section{RESOLUCุÃO DE PROBLEMAS NO ENSINO DE CIÊNCIAS}

Este trabalho compõe uma das etapas de uma pesquisa de Doutorado, que possui como um dos objetivos analisar as contribuições da metodologia de Resolução de Problemas (RP) no desenvolvimento de conhecimentos conceituais, procedimentais e atitudinais (ZABALA, 1998), bem como da autonomia (ZABALA, 1998; FREIRE, 1998) dos alunos de diferentes etapas e modalidades da Educação Básica (EB). Para tanto, elaboramos problemas para serem aplicados com alunos do Ensino Fundamental (RIBEIRO; PASSOS; SALGADO, 2019a), Ensino Médio regular (RIBEIRO; PASSOS; SALGADO, 2018a), Ensino Médio modalidade Educação de Jovens e Adultos (EJA) (RIBEIRO; PASSOS; SALGADO, 2019b) e Ensino Médio profissionalizante de um curso técnico em Química.

Ao longo da pesquisa e com o aprofundamento teórico obtido com os trabalhos de revisão bibliográfica empreendidos, pudemos identificar dados teóricos e empíricos promissores referentes ao uso da RP no Ensino de Ciências e Química, assim como na formação de professores da área (DOMIN; BODNER, 2012; FERNANDES; CAMPOS, 2017; GOI; SANTOS, 2014; LIMA; ARENAS; PASSOS, 2017).

Nesse sentido, alguns autores se destacaram na fundamentação desses estudos, tais como: Larry Laudan, Juan Ignacio Pozo, María Del Puy Pérez Echeverría, Miguel Angel Gómez Crespo, Maria Mercedes Martínez Aznar e Daniel Gil-Perez. As contribuições desses pesquisadores são expressivas no campo epistemológico das Ciências (LAUDAN, 1977; BATISTA; PEDUZZI, 2019), assim como na Didática das Ciências ao apresentar o conceito, a classificação e os tipos de problemas (ECHEVERRÍA; POZO, 1998; POZO, 1998; POZO; CRESPO, 1998; POZO; CRESPO, 2009, POZO, 2016), nas etapas necessárias para que a RP seja satisfatória (ECHEVERRÍA; POZO, 1998; POZO; CRESPO, 2009, POZO, 2016), e como guiar os alunos a tratar as situações-problema para que sejam exitosos em sua tarefa de solucioná-las (GIL-PEREZ; MARTINEZ TORREGROSA, 1983, MARTÍNEZ; MARTÍNEZ AZNAR, 2014).

Entretanto, percebemos que existem escassas discussões na literatura sobre como elaborar bons problemas para serem utilizados nas aulas de Ciências. Sockalingam e Schmidt (2011), após ampla pesquisa sobre a temática, reforçam essa compreensão e apontam que os estudos realizados indicam que a elaboração de um bom problema leva à melhoria da aprendizagem. Os autores destacaram três fragilidades identificadas na literatura sobre os estudos realizados quanto às características dos enunciados dos problemas. A primeira é que eles geralmente são baseados em pressupostos teóricos e não em evidências práticas de aplicação em sala de aula. Outra, que as pesquisas empíricas se concentram em características específicas, como a complexidade e estrutura do enunciado. Ao fim, que os estudos que tentaram explorar a qualidade dos problemas em um nível mais amplo estão restritos a percepções de especialistas ou a considerações teóricas a priori.

Para mitigar essas fragilidades, os autores sinalizam para a necessidade de estudos com o objetivo de investigar as percepções de professores e alunos sobre as características associadas com bons enunciados de problemas.

Convergindo para esse pensamento e como consequência das experiências empreendidas durante o doutoramento, percebemos a necessidade de se construir 
enunciados bem estruturados para auxiliar o professor e o aluno no entendimento e compreensão do que precisa ser resolvido, dessa maneira, podendo favorecer as potencialidades da metodologia da RP na EB.

Nesse contexto, o objetivo deste artigo é apresentar as características fundamentais de um problema para ser considerado eficaz para o Ensino de Ciências. Para isso, o presente estudo descreverá por que essas características devem ser consideradas quando elaboramos um problema no âmbito da educação científica, e exemplificará, através de três enunciados, como podemos estruturar essas características nos problemas construídos. Assim, pretendemos com esse artigo de cunho teórico oferecer subsídios aos professores na elaboração, produção e utilização de problemas investigativos em suas aulas. É pertinente salientar que as proposições teóricas apresentadas neste artigo são originadas da interlocução entre os aportes teóricos que fundamentaram a pesquisa de doutorado, como um todo, e os resultados da aplicação dos problemas em contexto real de sala de aula. As análises sobre as contribuições da sequência didática implementada com os estudantes dos diferentes níveis de ensino da EB foram apresentadas em estudos anteriores (RIBEIRO; PASSOS; SALGADO, 2018a, 2019a, 2019b). Este artigo visa apresentar as características de um Problema Eficaz e exemplificar com três problemas utilizados no contexto descrito nos trabalhos supracitados.

Durante a construção desses problemas, decidimos elaborar enunciados que contextualizassem a temática a ser tratada, que o assunto levasse a uma reflexão crítica, motivando os educandos para a resolução do problema proposto, além de compor uma proposição passível de ser compreendida, questionada, pesquisada, discutida com o objetivo de que os aprendizes chegassem a uma tomada de decisão e, finalmente, a uma solução adequada para o problema apresentado. Destacamos que as características apresentadas neste trabalho como fundamentais de um Problema Eficaz foram utilizadas para descrever os enunciados dos problemas de um estudo preliminar publicado no $38^{\circ}$ EDEQ (RIBEIRO; PASSOS; SALGADO, 2018b). Entretanto, neste artigo buscamos articular tais características com o referencial teórico que embasa nossas investigações.

\section{TIPOLOGIAS, CARACTERISTICASECLASSIFICAC̣̃̃ES DOS ENUNCIADOS DOS PROBLEMAS}

Laudan (1977) descreve aspectos importantes relacionados à epistemologia da RP em sua obra "Progress and Its Problems". Para esse estudioso, a "ciência é em essência uma atividade de resolução de problemas” (1977, p 11). Dessa maneira, faz-se necessário que os pesquisadores do campo da educação científica compreendam a Ciência como uma atividade de RP, pois essa atividade é capaz de desenvolver um progresso cognitivo relacionado com as aspirações intelectuais científicas. Visto que, avança pelo modo como resolve, adequadamente ou não, uma série de problemas gerados no ambiente social.

Ademais, Laudan (1977) desenvolveu uma taxonomia para os problemas na qual os identificou em empíricos e conceituais. Essa classificação torna mais clara a necessidade de relação dos processos utilizados na construção de conceitos científicos com os propósitos do uso de problemas no contexto educacional.

Convergindo para essa compreensão, Batista e Peduzzi (2019) apontam que os aportes epistemológicos de Larry Laudan são utilizados, entre outros fatores, 
para fundamentar estudos sobre implicações de práticas docentes para o Ensino de Ciências. No que diz respeito à literatura da RP, encontram-se diversas categorizações para os enunciados dos problemas. De acordo com Echeverría e Pozo (1998, p.16), uma circunstância apenas "pode ser concebida como um problema na medida em que exista um reconhecimento dela como tal, e na medida em que não disponhamos de procedimentos automáticos que nos permitam solucioná-lo de forma mais ou menos imediata", sem determinar, "de alguma forma, um processo de reflexão ou uma tomada de decisões sobre a sequência de passos a serem seguidos". Além disso, "um problema é, de certa forma, uma situação nova ou diferente do que já foi aprendido, que requer a utilização estratégica de técnicas já conhecidas."

Os pesquisadores Echeverría e Pozo (1998) estabelecem os problemas tendo em vista a área na qual estão inseridos, do conteúdo, dos tipos de operações e dos processos utilizados com o objetivo de resolvê-los. Os problemas podem ser classificados como dedutivos ou indutivos, de acordo com o tipo de raciocínio que a pessoa acionará na resolução do problema, e como definidos ou indefinidos. Assim sendo, diz-se que um problema é definido quando é de fácil identificação e solução; já um problema mal definido ou indefinido é aquele cujas etapas a serem seguidas são menos claras e específicas, podendo-se chegar a diversas soluções. Os problemas bem definidos são questões semelhantes aos exercícios, dessa forma os educandos conhecem os passos a serem seguidos e o ponto que se quer atingir. Os estudiosos, da mesma maneira, afirmam que não existem problemas totalmente mal definidos, caso contrário seriam problemas sem solução.

Já Pozo e Crespo (1998), classificam os problemas em três categorias: os problemas escolares, os problemas científicos e os problemas do cotidiano. Para esses autores, os problemas escolares podem ter caráter de uma investigação fechada, sendo que os recursos são dados pelo docente, mas pertence ao aluno a função de elaborar suas conclusões. Os problemas escolares servem de ponte entre os objetivos dos problemas científicos (os conteúdos científicos a serem trabalhados) e dos problemas cotidianos (circunstâncias da vida real). Segundo Pozo e Crespo, "o número de situações cotidianas que apresentam problemas relacionados com o funcionamento da natureza e da tecnologia seria infindável” (1998, p. 69). Os mesmos autores explicam que, quando temos em vista a maneira pela qual os problemas são tratados em sala de aula, assim como as metas educacionais no contexto do currículo e as estratégias de resolução, os problemas escolares podem ser classificados em três tipos: problemas qualitativos, problemas quantitativos e pequenas pesquisas. Caracterizam-se como problemas qualitativos aqueles cuja resolução acontece por intermédio de raciocínios teóricos sem necessidade de cálculos numéricos ou manipulações experimentais. Na maioria das vezes, configuram-se como problemas abertos, nos quais se deve antever ou explicar uma situação ou um fato. Já os problemas quantitativos utilizam dados numéricos. Embora o resultado possa não ocorrer em termos numéricos, a estratégia está centrada no cálculo matemático, na comparação de dados e no emprego de fórmulas (POZO; CRESPO, 1998).

Além do mais, os problemas escolares podem ser caracterizados em abertos, semiabertos e fechados. Os problemas abertos são considerados amplos, ensejando diversas interpretações e maneiras de serem resolvidos. No que diz respeito aos problemas semiabertos, são fornecidas informações que restringem 
o problema, entretanto, deixam que os próprios estudantes congreguem ideias e estratégias com as quais seja possível definir e resolver o trabalho. Já os enunciados dos problemas fechados restringem de tal forma, que sua resolução demanda modos mais ou menos pré-estabelecidos (POZO; CRESPO, 1998).

Para Echeverría e Pozo (1998), há de se seguir algumas etapas para que a RP dos problemas escolares seja satisfatória. A primeira etapa, no que diz respeito à RP, está relacionada à compreensão desses problemas. Entretanto, não basta apenas entender as palavras, a linguagem, o símbolo deve-se, também, assumir a situação e passar a ter uma disposição para chegar à solução desejada. Em seguida, há de se idealizar uma estratégia que auxilie a resolver o problema. A próxima etapa deve consistir em desenvolver essa fase anteriormente elaborada e, finalmente, o processo de solução (visão retrospectiva), no qual o estudante afere se a finalidade à qual se destina foi alcançada, fazendo, assim, uma revisão dos procedimentos.

Esse aprofundamento teórico sobre a perspectiva epistemológica e as classificações dos tipos de problemas e das pesquisas sobre RP no Ensino de Ciências foi fundamental para entendermos como poderíamos aplicar nosso estudo pedagogicamente dentro do espaço escolar. Percebemos, principalmente, a importância do papel dos professores na mediação pedagógica com o uso da metodologia de RP no Ensino de Ciências. A ação decisiva que o docente exerce na mediação das atividades propostas e o conhecimento do educando com a finalidade de auxiliálo a desenvolver e a construir seus próprios conhecimentos. Dessa maneira, muitos professores estão buscando na RP uma alternativa metodológica para aperfeiçoar o processo de ensino e aprendizagem, pois é um dos modos de fazer com que o educando reflita, proponha e planeje ações de resolução para as situações propostas.

Considerando que os problemas desempenham um papel importante no processo de aprendizagem, Sockalingam, Rotgnas e Schmidt (2011) destacaram que é fundamental que os problemas sejam de alta qualidade, ou seja, eficazes para atingir os objetivos das atividades propostas. Os autores apontam que em investigações sobre as relações e influências entre diferentes fatores da resolução de problemas no desempenho acadêmico, a qualidade dos problemas, a atuação docente e o conhecimento prévio dos alunos foram categorizados como fatores fundamentais. Ademais, destacaram que os problemas têm o maior impacto na aprendizagem dos alunos em processos fundamentados na resolução de problemas. Segundo os autores, o que importa num enunciado é a clareza do que deve ser investigado, para ajudar os alunos em sua aprendizagem. Essa característica seria mais importante do que ter um problema que usa um contexto familiar que os alunos podem se identificar (SOCKALINGAM; HOTGNAS; SCHMIDT, 2011).

Entretanto, em nossas investigações, percebemos que existem escassas discussões na literatura sobre as características que devem compor o enunciado para tal ser considerado eficaz para as aulas de Ciências. Dessa maneira, enfatizamos a relevância desde artigo, que apresentará as características do que denominamos "Problema Eficaz", visando auxiliar os professores que desejam iniciar ou aperfeiçoar a construção de problemas investigativos no Ensino de Ciências. 


\section{APORTE TEÓRICO DAS CARACTERÍSTICAS FUNDAMENTAIS DE UM PROBLEMA EFICAZ}

Diante do aporte teórico e dos resultados práticos das investigações realizadas (RIBEIRO; PASSOS; SALGADO, 2018a; 2019a; 2019b), compreendemos que são vários os fatores que influenciam em lograr êxito nas atividades baseadas na RP, tais como: os objetivos que queremos alcançar, os conteúdos que queremos trabalhar, os conhecimentos dos quais queremos que os alunos se apropriem, a sequência didática utilizada, o papel da mediação pedagógica, as classificações do(s) problema(s), as características do(s) problema(s) utilizado(s), etc. Nesse âmbito, o planejamento e a execução da proposta pedagógica são fundamentais para o sucesso da atividade.

Enfim, tendo em vista as pesquisas realizadas com o uso da RP e principalmente dos aportes da literatura chegamos a um consenso de que um Problema Eficaz é aquele que apresenta as quatro características a seguir.

\section{Um Problema Eficaz contextualiza a temática à realidade do aluno e aproxima-o da questão proposta}

A perspectiva de contextualização pode fundamentar-se em diferentes correntes teóricas, como o enfoque na Ciência, Tecnologia e Sociedade (CTS), na proposta de educação transformadora de Paulo Freire (1921-1997), a partir do aporte da história e filosofia das ciências, ou ainda na contextualização não redutiva, a partir do cotidiano, como no caso deste trabalho (WARTHA; SILVA; BEJARANO, 2013). A contextualização, a partir do cotidiano, favorece que o estudante atribua significado àquilo que aprende e relacione o que está sendo discutido com sua experiência de vida. Consideramos que, por intermédio da contextualização, o estudante relaciona teoria e prática (WARTHA; SILVA; BEJARANO, 2013). Para tanto, uma educação que pretenda um cidadão crítico e reflexivo e exija maior participação do educando no que tange ao ensino e aprendizagem necessita de um processo que favoreça a reflexão acerca da resolução de problemas contextualizados que possam ser convergentes à sua realidade, motivando-os a buscar soluções (POZO; CRESPO, 2009).

Assim, a contextualização, a partir do cotidiano, é considerada um princípio norteador e não apenas uma exemplificação de aplicação do conteúdo estudado (WARTHA; SILVA; BEJARANO, 2013). Por esse motivo, devemos ter em mente na construção de um problema que a contextualização se faz necessária para que a aprendizagem favoreça a formação de um cidadão crítico e reflexivo.

\section{Um Problema Eficaz suscita a reflexão crítica acerca do assunto abordado}

Entendemos que os alunos da EB devem aprender durante as suas vidas escolares a se posicionarem perante questões sociais, políticas, econômicas, ambientais, sobre os variados assuntos que são trabalhados na escola e que exigem essas reflexões (LOUREIRO; TOZONI-REIS, 2016). Nesse contexto, percebemos que um problema com essa característica pode ajudar no desenvolvimento do aluno, na capacidade de resolver situações desafiadoras, na interação nos grupos que buscam a solução de um problema, no aprimoramento da comunicação, assim como 
no aperfeiçoamento da criatividade e do senso crítico (MARTÍNEZ; MARTÍNEZ AZNAR, 2014). Quando construímos um problema que será utilizado nas aulas de Ciências, precisamos ter em mente que ele deve incentivar a habilidade de investigar, de refletir criticamente e de dar a possibilidade de os estudantes criarem e construírem seus conhecimentos perante o problema a ser solucionado.

A sociedade atual requer indivíduos que sejam capazes de intervir no desenvolvimento da humanidade de maneira crítica e criativa com o objetivo de construirmos uma sociedade mais justa, buscando uma melhoria na qualidade de vida dos cidadãos (COSTA; ECHEVERRIA; RIBEIRO, 2017). A nossa proposta é que uma das formas mais acessíveis de fazer com que os educandos desenvolvam a reflexão crítica sobre o problema a ser resolvido é a metodologia da RP. A resolução de um Problema Eficaz implica um processo de reflexão crítica acerca da questão a ser resolvida (MARTÍNEZ; MARTINEZ AZNAR, 2014), levando, muitas vezes, à tomada de posições sociais, políticas e econômicas, conforme a temática do problema proposto. Esse tipo de metodologia desenvolve no aluno autonomia (FREIRE, 1998), aptidão em resolver problemas, colaboração, confiança, protagonismo, senso crítico, aprendizado envolvente, empatia, responsabilidade e participação.

Para que tenhamos alunos que desenvolvam reflexão crítica, a escola deve trabalhar um currículo no qual a proposta política pedagógica esteja baseada em uma perspectiva crítica (LOUREIRO; TOZONI-REIS, 2016; COSTA; ECHEVERRIA; RIBEIRO, 2017), a qual desafie o aluno a pensar criticamente a realidade social, política e histórica. Entendemos que um Problema Eficaz pode ajudar os alunos a desenvolverem essa característica reflexiva.

Ademais, percebemos que a educação crítica é orientada para a tomada de decisões e o exercício de prática de uma responsabilidade social e política (LOUREIRO; TOZONI-REIS, 2016; COSTA; ECHEVERRIA; RIBEIRO, 2017). Consideramos que, na medida que conseguimos, por intermédio da metodologia de ensino, fazer com que o educando seja capaz de refletir criticamente sobre a realidade que o cerca, melhores condições ele terá de atuar no que diz respeito a essa realidade, podendo, inclusive, modificá-la, tendo como objetivo o bem comum.

\section{Um Problema Eficaz motiva 0 aluno a buscar soluções}

Consideramos que a motivação se faz necessária tanto para que a aprendizagem ocorra quanto para que sejam colocados em ação os comportamentos e habilidades que foram aprendidos. A motivação é uma condição inerente ao ser humano, levando-o a realizar ou continuar realizando uma tarefa (BARRERA, 2010). A motivação está relacionada ao impulsionamento de uma ação, ou seja, àquilo que move um comportamento. Nesse sentido, compreendemos a motivação como a responsável pelo começo, manutenção e/ou término de uma ação (FERNANDES; CAMPOS, 2017). Assim sendo, notamos que a motivação é um elemento que compõe o indivíduo e as atividades que ele realiza em diferentes contextos, assim como o contexto escolar sobre o qual recai o nosso estudo.

Pensando na origem da palavra motivação, o vocábulo provém do latim e significa mover. Oliveira (2008) refere-se à motivação como uma força que incita um indivíduo a atingir uma determinada meta. Esse mesmo autor esclarece-nos que "a 
motivação é o que coloca um sujeito em movimento em direção a esse fim proposto. A motivação tem sido vista como um fator psicológico, um conjunto de fatores, ou um processo que varia de pessoa para pessoa" (OLIVEIRA, 2008, p. 37).

A revisão da literatura realizada por Lourenço e Paiva (2010) refere-se à motivação como um fator além de uma pré-condição importante, como as teorias mais antigas acerca da aprendizagem a consideravam. Atualmente as investigações permitem concluir que há uma reciprocidade entre a aprendizagem e a motivação, visto que "a motivação pode interferir na aprendizagem e no desempenho, bem como a aprendizagem pode produzir um efeito na motivação” (LOURENÇO; PAIVA, 2010, p. 134).

Desta forma, compreendemos que a motivação não é somente um aspecto interno, mas que pode ser externo ao sujeito, algo que pode mobilizar os recursos cognitivos dos estudantes. Consideramos que diferentes aspectos, como a atuação e mediação do professor, um ambiente aprazível na escola, assim como um enunciado de Problema Eficaz pode gerar ou aumentar a motivação dos estudantes no processo de aprendizagem. Lourenço e Paiva (2010) pautam-se na teoria de Lev Vygostky (1896-1934) ao apontarem que o pensamento propriamente dito é fruto da motivação, como nossas vontades e necessidades. Nesse sentido, o problema externo, ao ser apropriado pelo sujeito, pode gerar a formação de funções psicológicas, logo, internas, ou seja, para Vygotsky, o externo se faz interno nos sujeitos.

Corroborando com esta compreensão, Fernandes e Campos (2017) apontam que o fator motivacional do problema está relacionado ao conteúdo do enunciado, logo este deve ser relevante e precisa estimular o estudante a resolvêlo. Estando motivados para a realização de determinada tarefa, os aprendizes podem apresentar maior empenho e, por consequência, envolver-se mais no processo de busca por uma solução para um problema escolar ou da sua vivência. Dessa maneira, afirmamos que é fundamental que um problema deve favorecer a motivação do aluno na busca à(s) resposta(s) dessa situação desafiadora.

\section{Um Problema Eficaz favorece a proposição de hipóteses, pesquisas, investigações, questionamentos, discussões, levando a uma tomada de decisão}

Para concretizarmos esse objetivo, devemos ter em mente que resolver um problema pressupõe que o aluno elabore um ou vários procedimentos de resolução, por exemplo, realizar simulações, fazer tentativas, formular hipóteses (ECHEVERRÍA; POZO, 1998). E para a elaboração desses procedimentos, entendemos que um problema deve ser formulado de maneira convergente aos apontamentos de Pozo e Crespo (1998) quanto aos enunciados semiabertos, os quais são estruturados fornecendo clareza nos princípios gerais necessários para a solução do problema, permitindo aos alunos a análise das diferentes formas de modelação de resolução. Desta forma, pode mobilizar a elaboração de hipóteses, pesquisas, investigações, discussões para que os educandos tomem uma decisão e cheguem a uma resposta adequada à questão proposta. Dessa maneira, os aprendizes podem estabelecer como e o que de fato devem pesquisar, identificam os elementos e os instrumentos que serão utilizados no decorrer do trabalho (GOI; SANTOS, 2014).

De acordo com os pressupostos de Laudan (1977), a Ciência tem como meta elaborar teorias com elevada taxa de eficiência na resolução de problemas, e não 
estritamente com a confirmação ou refutação das teorias. Partindo dessa natureza epistemológica racionalista, a metodologia de Resolução de Problemas possibilita a modelação de diferentes percursos para a resolução de um problema teórico ou empírico e, ainda, a obtenção de distintas resoluções para um mesmo enunciado.

Nesse contexto, um dos objetivos de práticas pedagógicas baseadas na RP é fazer com que os alunos sejam capazes de enfrentar situações cotidianas, analisando-as e interpretando-as através dos modelos conceituais e também dos procedimentos próprios da Ciência (POZO; CRESPO, 1998).

\section{UMA ESTRUTURA POSSÍVEL PARA UM PROBLEMA EFICAZ}

Frente ao exposto nos itens anteriores, consideramos que o processo de ensino e aprendizagem de Ciências pode ser favorecido com o uso da Resolução de Problemas, desde que o enunciado do problema apresente as quatro características para ser considerado um "Problema Eficaz", sendo estas: contextualização, reflexão crítica, motivação e investigação. Ademais, destacamos que essas características estão interligadas e em sinergia, pois uma depende da outra para que o problema esteja bem estruturado e, dessa maneira, possa potencializar as atividades baseadas na RP.

Apresentaremos as características de um Problema Eficaz numa determinada ordem, entretanto essa disposição possui apenas fins didáticos. Elas podem, conforme a elaboração pretendida, aparecer em posições diferenciadas da que apresentaremos, desde que não haja prejuízo à compreensão do problema. Essa flexibilidade da disposição das características de um Problema Eficaz deve-se ao fato de elas estarem intimamente relacionadas, como mostraremos no decorrer deste estudo. Consideramos que em uma frase ou trecho do problema possa conter duas ou mais características de um Problema Eficaz, tendo em vista o conhecimento do professor em relação ao assunto que deseja abordar, utilizando a metodologia da RP e relacionando aos objetivos que pretende com a resolução do problema.

Exemplificaremos como podemos estruturar e construir um Problema Eficaz a partir de três problemas abordando a temática ambiental agrotóxicos. A seleção da temática agrotóxicos deve-se ao fato de que o Brasil é um dos maiores consumidores de agrotóxicos do mundo e responsável por uma produção agrícola de reconhecimento internacional (RIBEIRO, 2018). Cabe ressaltar que é fundamental que o docente saiba quais os conhecimentos que almeja que seus alunos se apropriem sobre determinado assunto, quando se inicia uma atividade baseada na RP. Assim, poderá decidir quantos problemas e quantos períodos de aula utilizará. Ainda, entendemos que durante a intervenção pedagógica, o número de problemas pode variar se o professor perceber essa necessidade. Essa percepção está relacionada com a compreensão e assimilação dos conteúdos pelos alunos.

Nas explicações a seguir, exemplificaremos como podemos abordar uma temática das Ciências ampla e complexa, a partir de problemas estruturados com as características de um Problema Eficaz. Perceberemos essa amplitude e complexidade do assunto nos esclarecimentos que se seguem.

A primeira característica de um Problema Eficaz (Figura 1), contextualização do problema, situa o educando na questão a ser resolvida: aproxima o estudante da realidade da fome no mundo, apontando um dado de 
que 815 milhões de pessoas não possuem acesso à alimentação básica. Fato que é usado para justificar o uso expressivo de agrotóxicos na agricultura. Uma das consequências do uso desenfreado dos agrotóxicos é a contaminação dos pinguins e focas na Antártida por DDT, ${ }^{1}$ local onde essa substância química não é utilizada. Esse dado é alarmante, uma vez que existem, na atualidade, grandes avanços econômicos, técnicos, sociais e tecnológicos que poderiam aplacar a fome mundial. De acordo com subsídios mais atuais da Organização das Nações Unidas para a Alimentação e a Agricultura (FAO), de setembro de 2018, houve um acréscimo no número de seres humanos que passam fome no mundo. Tendo em vista informações divulgadas por essa organização, o número subiu de 815 milhões de indivíduos, em 2016, para quase 821 milhões em 2017 (FAO, 2019). O relatório aponta que uma em cada nove pessoas no planeta foi vítima de fome (FAO, 2019).

A contextualização, via de regra, é o ato de associar o conhecimento à sua origem, assim como à sua aplicação. Ela é de suma importância para que se impeça que algo que se deseja abordar fique fragmentado ou desconexo, dificultando o aprendizado (WARTHA; SILVA; BEJARANO, 2013). Dessa forma, a situação apresentada ressalta aos aprendizes a importância da produção de alimentos em larga escala para a humanidade, levando-os a compreender e a relacionar as próximas informações que serão dadas no problema proposto a eles. Enfim, trata-se de uma temática que pode ser considerada como potencialmente problematizadora de um contexto/problema cotidiano.

Figura 01. Primeiro problema com as características de um Problema Eficaz

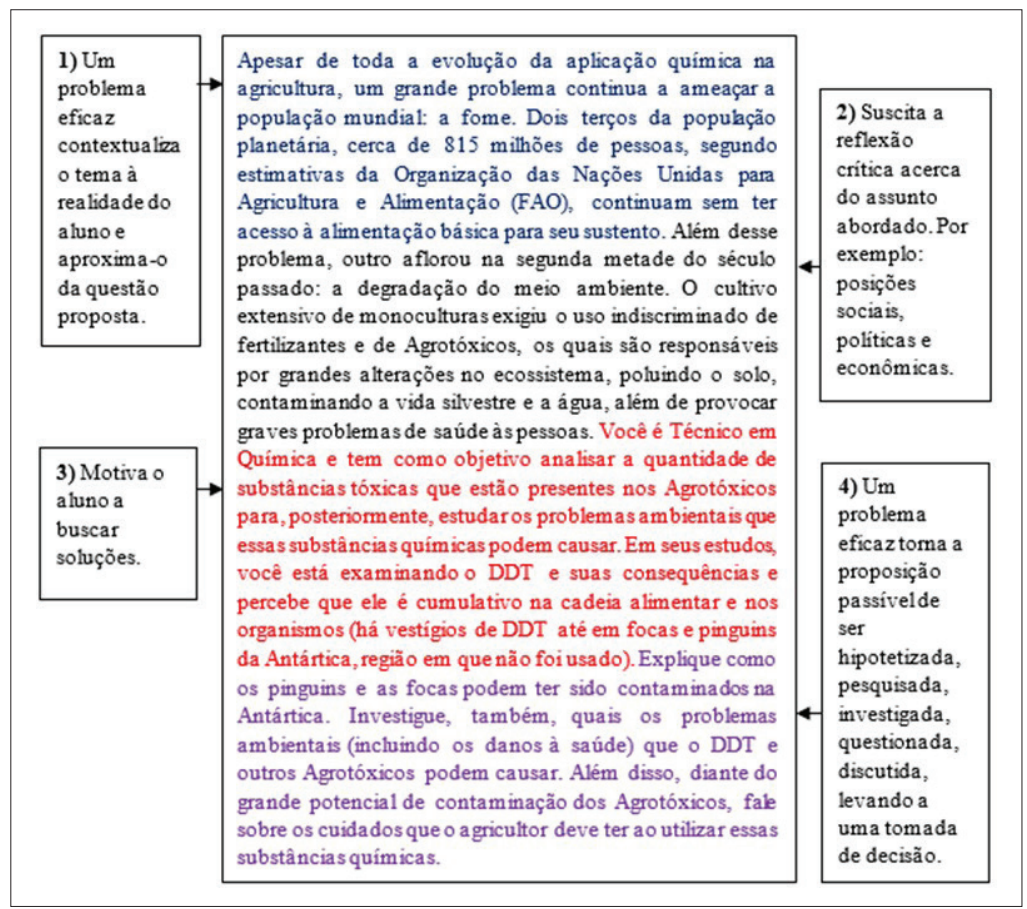

Fonte: Elaborado pelos autores. 
A segunda característica (Figura 1) leva o aluno a diversos tipos de reflexão crítica (LOUREIRO; TOZONI-REIS, 2016), tendo em vista o aumento do cultivo de alimentos para nutrir a população mundial cada vez mais crescente. Como consequência, há degradação do meio ambiente e a utilização imoderada de agrotóxicos. Essa informação favorece uma discussão crítica e reflexiva sobre aspectos sociais, políticos e econômicos relacionados à destruição do meio ambiente, tendo em vista o cultivo extensivo de monoculturas. Essa reflexão certamente prepara os educandos para a terceira característica de um Problema Eficaz, cujo enfoque na questão apresentada é a contaminação por DDT de pinguins na Antártica, região onde não se faz uso dessa substância química. Nesse sentido, é necessário que a educação ambiental seja vista como um instrumento que guie para uma tomada de consciência dos cidadãos (COSTA; ECHEVERRIA; RIBEIRO, 2017).

No que tange à terceira característica de um Problema Eficaz (Figura 1), a motivação, podemos dizer que motivação é um aspecto fundamental no ato de ensinar e aprender, é um processo no qual o indivíduo toma uma decisão frente às variadas questões as quais tem de confrontar. Com o intuito de sentir-se motivado, o educando necessita de uma ação, de um motivo que o faça conquistar um objetivo. De acordo com Bzuneck (2000, p. 9), "a motivação, ou motivo, é aquilo que move uma pessoa ou que a põe em ação ou a faz mudar de curso". Podemos dizer que a motivação é um processo e, por conseguinte, produz ou estimula uma conduta que sustente uma atividade progressiva a qual canaliza essa atividade para um dado sentido (FERNANDES; CAMPOS, 2017). Assim sendo, estando o problema contextualizado e dando a oportunidade aos estudantes de realizarem uma reflexão crítica sobre a temática, há possibilidades mais prováveis de gerar motivação para que os aprendizes possam solucionar o problema. Nesse caso, os estudantes podem assumir o papel de futuros Técnicos em Química, ao investigarem sobre o DDT e as consequências de seu uso no ambiente como no caso dos pinguins e focas na Antártida.

Referente à quarta característica de um Problema Eficaz (Figura 1), percebemos que, a partir da nossa proposta de investigação, ou seja, explicar como os pinguins e focas da Antártida podem ter sido contaminados com DDT, investigar os problemas ambientais, inclusive os danos à saúde que o DDT pode causar, além dos cuidados que os agricultores devem ter na aplicação de agrotóxicos, permite que os educandos elaborem hipóteses, pesquisem, questionem, discutam e cheguem a uma conclusão a respeito do problema a eles destinado.

Segundo Pozo e Echeverría (1998), “[...]O ensino baseado na solução de problemas pressupõe promover nos alunos o domínio de procedimentos, assim como a utilização dos conhecimentos disponíveis, para dar resposta a situações variáveis e diferentes" (p. 09). Nesse contexto, os educandos têm, diante de si, um problema a ser solucionado, uma questão que envolve um grave problema: O uso do DDT.

As consequências do DDT em animais são evidentes, principalmente em aves, uma vez que os ovos apresentam a espessura da casca reduzida, prejudicando a reprodução (SANTOS; MÓL, 2013). Além disso, apresenta redução no tamanho cerebral dos embriões. Sabemos que o DDT é um inseticida de baixo custo e essa substância leva de 4 a 30 anos para se degradar, afetando a fauna e a flora, infiltrando-se na água e contaminando mananciais (SANTOS; MÓL, 2013). Estudos revelam que os pesticidas organoclorados, como o DDT, agem sobre 
o sistema nervoso central, implicando alterações de comportamento, distúrbios sensoriais, do equilíbrio, da atividade da musculatura involuntária, assim como depressão dos centros vitais, em especial, da respiração (BRASIL, 1997). Da mesma forma, há evidências, na literatura médica, da relação entre DDT e câncer de pâncreas, devido a exposições em grandes quantidades dessa substância química (MESQUITA, 2001; SOUZA, 2006). Devido a tantas consequências danosas ao meio ambiente e à saúde humana, a utilização do DDT foi restrita a casos especiais, no que diz respeito a controle de vetores de doenças pela Convenção de Estocolmo (SILVA; GUIMARÃES, 2010). Essa convenção se realiza com o intuito de discutir acerca de Poluentes Orgânicos Persistentes, denominados POPs. Em 2009, o Brasil, que é signatário dessa convenção, eliminou o DDT, desautorizando sua fabricação, importação, exportação, manutenção em estoque, comercialização e uso (PEREIRA; CARSON, 2012).

A contextualização do problema 2 (Figura 2) trata da devastação de áreas verdes para o plantio de alimentos com consequências danosas ao meio ambiente, além da utilização indiscriminada de agrotóxicos, trazendo, da mesma forma, resultados prejudiciais ao meio em que vivemos. A contextualização nesse exemplo é relevante pelo fato de atribuir um sentido preventivo àquilo ao qual os estudantes estarão expostos. É, na realidade, uma forma de designar as circunstâncias que estão ao redor de um acontecimento, situação ou fato (WARTHA; SILVA; BEJARANO, 2013).

Sabemos que a exploração ambiental está intimamente relacionada à evolução do intrincado desenvolvimento tecnológico, científico e econômico o qual, por diversas vezes, tem modificado, de maneira irreversível, o cenário do planeta e conduzido a processos degenerativos profundos da natureza (RAMPAZZO, 1997). Entre os processos degenerativos profundos da natureza, Ehlers (1999) evidencia a erosão e a perda da fertilidade dos solos, a destruição florestal, a dilapidação do patrimônio genético e da biodiversidade, a contaminação dos solos, da água, dos animais silvestres, do homem do campo, assim como dos alimentos.

Contextualizado o problema, situando os educandos à questão que devem resolver, a segunda característica do Problema Eficaz (Figura 2) pode levar os alunos a refletir sobre a temática, qual seja: aliar a produção de alimentos à preservação ambiental. Essa reflexão crítica pode ser fomentada pelas discussões nos grupos, no levantamento dos aspectos sociais, políticos e econômicos, envolvidos na produção de alimentos e na preservação ambiental. 
Figura 02. Segundo problema com as características de um Problema Eficaz

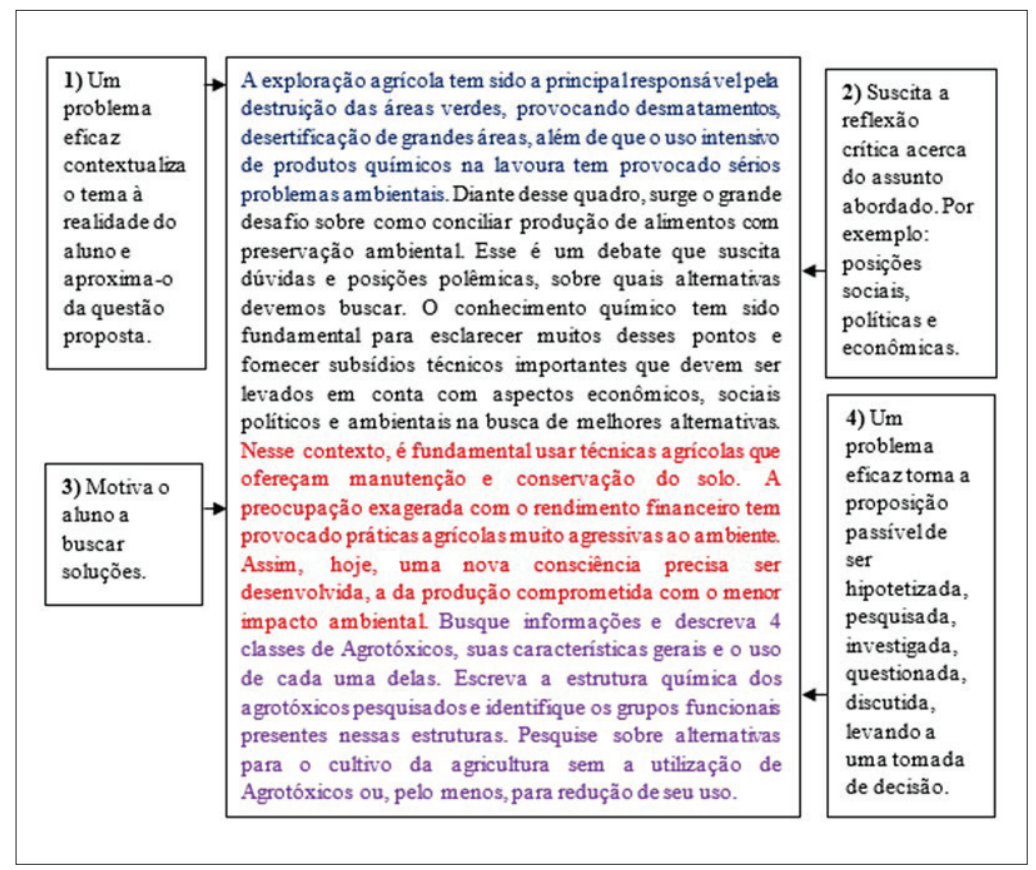

Fonte: Elaborado pelos autores.

Preiss, Vasconcellos e Schneider (2018) afirmam que o planeta possui 7,3 bilhões de habitantes, dos quais 54\% residem em áreas urbanas. Para mais, a expectativa populacional é de chegar a 9,5 bilhões no ano de 2050, sendo que mais de $70 \%$ nas cidades. Como podemos perceber, há um enorme número de pessoas a alimentar. Dessa forma, é importante a utilização de práticas de conservação e preservação ambiental, com o intuito de preservar a fertilidade do solo, assim como as condições climáticas favoráveis. Sabemos que, para a produção de alimentos, os agrossistemas, tais como lavoura, pastagens, exigem a modificação do sistema natural. Essa ação tem como consequência a transformação dos ecossistemas, havendo a remoção da cobertura vegetal, revolvimento do solo (aração, gradeação, semeadura, plantio, cultivo), aplicação de fertilizantes, de defensivos com o objetivo de combater doenças e pragas. Tudo isso tem como resultado contaminação do solo, do ar e das águas, erosão, compactação e diminuição da permeabilidade do solo, entre outros. Por esses motivos, temos de viabilizar uma agricultura sustentável.

No que diz respeito à motivação (Figura 2) para a resolução desse problema, as informações fornecidas no enunciado podem mobilizar os educandos na busca por uma solução que utilize técnicas agrícolas que mantenham e conservem o solo, tendo uma produção que leve em consideração um menor impacto ambiental. Como apontam Lourenço e Paiva (2010), temos que considerar a recíproca entre a aprendizagem e a motivação. Neste âmbito, ao conhecer sobre as possibilidades de práticas agrícolas menos impactantes ao ambiente, o estudante pode buscar um aprofundamento conceitual sobre tais, pois passa a reconhecer essa demanda como 
um interesse seu, um fator que pode gerar a motivação para resolução do problema. Em suma, a motivação pode ser compreendida como o aspeto dinâmico ou energético da ação, é aquilo que impulsiona o comportamento (BARRERA, 2010).

Para que haja grande produção de alimentos, ocorre o desmatamento, extensas áreas de terras são utilizadas para a monocultura, alterando de forma significativa o ambiente, tanto no que diz respeito à flora quanto à fauna. Ademais, existe a utilização indiscriminada de fertilizantes, herbicidas e pesticidas na agricultura, ocasionando sérias consequências à saúde humana e ao meio ambiente. Dessa maneira, urge que se busquem alternativas com o objetivo de que os impactos ambientais sejam minimizados, como no caso da agricultura sustentável (LEWANDOWSKI; HARDTLEIN; KALTSCHMITT', 1999, citando a Conferência de Ministros Europeus de Meio Ambiente). Motivados para a tarefa, os alunos também são instigados a buscarem informações a respeito de classes de agrotóxicos, sua estrutura química, assim como os grupos funcionais presentes nas estruturas dos produtos químicos pesquisados.

Além disso, os educandos são levados a investigar acerca de alternativas para uma agricultura sem agrotóxicos ou com a diminuição de seu uso (quarta característica de um Problema Eficaz, Figura 2).

Epistemologicamente, quando os educandos entendem e aceitam que têm problemas para resolverem, sentem-se estimulados a buscar soluções para tais. Laudan (1977) destaca que o progresso da Ciência ocorre conforme esse itinerário de pesquisa. Assim, entendemos que os problemas não resolvidos mobilizam uma ação, pois transformar os problemas não resolvidos e anomalias em problemas resolvidos "é um dos modos pelos quais as teorias progressistas estabelecem suas credenciais científicas” (LAUDAN, 1977, p. 28).

A primeira parte do problema apresentado na Figura 3 nos remete à contextualização, ou seja, vincula o conhecimento à sua origem e à sua aplicação favorecendo a busca por soluções (POZO; CRESPO, 2009). Baseado nisso é que o conhecimento ganhará significado real para o aluno, pois é apresentado ao mesmo a respeito da agricultura sustentável, assunto que lhe diz respeito, pois é por intermédio da agricultura que satisfazemos nossa necessidade diária de alimentação, assim como sofremos as consequências de uma agricultura que traz danos ao meio ambiente e à nossa saúde pela utilização indiscriminada de agrotóxicos. As informações dessa primeira parte do enunciado ambientam os aprendizes à temática do problema, ou seja, a utilização de uma agricultura sustentável, economicamente viável e ecologicamente equilibrada. 
Figura 03. Terceiro problema com as características de um Problema Eficaz

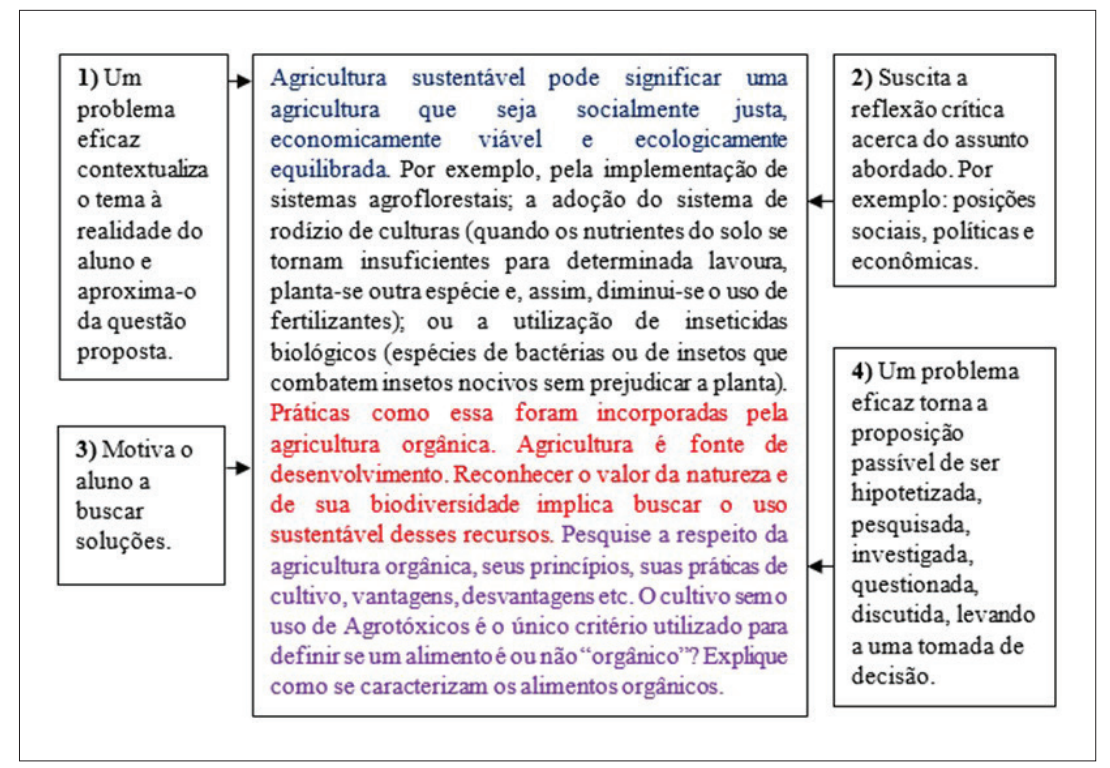

Fonte: Elaborado pelos autores.

A segunda parte do problema (Figura 3) pode levar os alunos a pensarem, refletirem sobre outras formas de agricultura que não agridem tanto o ambiente como a forma tradicional, utilizando menos agrotóxicos ou até mesmo não fazendo uso dessas substâncias químicas. Portanto, a agricultura sustentável é uma opção, já que está relacionada ao uso de um método de cultivo o qual respeita o meio ambiente e contribui para a sua preservação, não deixando de ser uma atividade economicamente viável e lucrativa. Dessa maneira, trata-se de um processo que proporciona a qualidade de vida e a capacidade de suprir as necessidades das gerações futuras, tendo em vista o cuidado da terra, da água e do ar. Berbel (2011) afirma que o educando, diante de problemas e/ou desafios, mobiliza o seu potencial na medida em que estuda com o intuito de compreendê-los e/ou superá-los, produzindo, consequentemente, conhecimento em função do que necessita responder ou equacionar. Durante esse processo, é possível que o estudante, gradativamente, desenvolva o espírito científico, o pensamento crítico, o pensamento reflexivo, adquira valores éticos, tornando-se autônomo na formação como ser humano, bem como em relação ao seu futuro profissional.

A terceira parte pode motivar (Figura 3) os educandos a buscarem uma solução mais harmônica, mais saudável para práticas agrícolas que não interfiram tanto no meio em que vivemos. Apesar de diversas denominações, as agriculturas alternativas se propagam no mundo e no Brasil por intermédio de diversas correntes. Entretanto, possuem o mesmo objetivo: promover mudanças tecnológicas e filosóficas na agricultura. Essa característica do Problema Eficaz favorece a motivação dos educandos, evidenciando que o reconhecimento do valor da natureza e sua biodiversidade acarreta a busca da utilização sustentável dos recursos do meio ambiente. De David (2018, pág. 122) afirma: "A sociedade precisa caminhar em direção à sustentabilidade de forma harmônica com desenvolvimento socioeconômico e 
ambiental, trabalhando sempre a prevenção e a preservação com atitudes individuais e coletivas." Nesse sentido, o enunciado do problema (fator externo) ao ser considerado como algo que o concerne, pode gerar a motivação para o desenvolvimento de funções psicológicas no processo de aprendizagem (fator interno), como pressupõe a teoria de aprendizagem de Lev Vygotsky (LOURENÇO; PAIVA, 2010).

Os questionamentos feitos na quarta característica de um Problema Eficaz (Figura 3) levam os alunos à prática, ou seja, à busca de uma solução. Para tanto, os aprendizes devem ser orientados a pesquisarem acerca da agricultura orgânica, seus princípios, suas práticas de cultivo, vantagens e desvantagens, assim como questionamentos relacionados ao que define um alimento orgânico. Sabemos que a agricultura orgânica é um processo produtivo que está comprometido com a organicidade e a sanidade da produção de alimentos vivos, com o intuito de preservar a saúde dos seres humanos (RIBEIRO, 2018). Para isso, usa tecnologias que são adequadas à realidade do local de produção. Esse tipo de agricultura não utiliza agrotóxicos e possibilita a restauração e manutenção da biodiversidade. Outrossim, utiliza fertilizantes naturais, rotatividade de culturas, uso racional da água, além de técnicas que possam ser adaptadas à realidade do local de cultivo. Nesse sentido, salientamos que os alunos podem desenvolver sua autonomia (FREIRE, 1998), com o conjunto de atividades necessárias para investigar e para chegar a uma solução adequada para problemas com essa natureza.

\section{ALGUMAS CONSIDERAC̣̃̃ES}

A partir dos estudos realizados sobre o uso da metodologia de RP, chegamos à conclusão de que um Problema Eficaz deve contemplar as quatro características descritas neste artigo: Contextualização (WARTHA; SILVA; BEJARANO, 2013), Reflexão Crítica (LOUREIRO; TOZONI-REIS, 2016; COSTA; ECHEVERRIA; RIBEIRO, 2017), Motivação (LOURENÇO; PAIVA, 2010) e proposição passível de favorecer a elaboração de hipóteses, ser investigada, questionada, discutida, levando a uma tomada de decisão (LAUDAN, 1977; POZO; CRESPO, 1998).

Neste artigo, apresentamos as características de um Problema Eficaz numa determinada ordem, entretanto essa disposição possui apenas fins didáticos. Elas podem, conforme a elaboração pretendida, aparecer em posições diferenciadas da que apresentamos, desde que não haja prejuízo à compreensão do problema. Essa flexibilidade da disposição das características de um Problema Eficaz devese ao fato de elas estarem intimamente relacionadas. A contextualização, no caso dos problemas trabalhados neste artigo, refere-se a situações do cotidiano numa perspectiva não redutiva. Isso, consequentemente, pode mobilizar os estudantes à reflexão crítica do problema ao qual deverá solucionar, já que está intimamente ligado ao seu dia a dia, favorecendo a motivação para buscar soluções à situação na qual está inserido. Devido a essas premissas, apontamos que as características de um Problema Eficaz atuam de forma sinergética e consonante. Consideramos que apenas a quarta característica, a proposição em si, não possa ser deslocada para outra posição, contudo nela podem constar as outras três características.

Para finalizarmos, sabemos que de nada adianta termos problemas bem formulados sobre determinados conteúdos com finalidades pedagógicas, se não 
tivermos um planejamento adequado para se trabalhar com a RP. Dessa maneira, é fundamental que o docente perceba a importância da sua formação continuada, buscando novas metodologias de ensino e aperfeiçoamento das suas práticas em sala de aula. Nesse contexto, e por toda nossa pesquisa realizada, entendemos que a RP é uma proposta pedagógica que permite fazer a associação do cotidiano dos aprendizes com os conteúdos escolares e, fazendo parte dessa metodologia de ensino, os problemas devem ser eficazes e realmente possibilitar que os alunos reflitam e sejam capazes de construir seu próprio conhecimento.

\section{REFERÊNCIAS}

BARRERA, S. D. Teorias cognitivas da motivação e sua relação com o desempenho escolar. Poíesis Pedagógic, São Paulo; v.8, n.2, p.159-175, 2010.

BATISTA, C. A. S.; PEDUZZI, L. O. Q. Concepções epistemológicas de Larry Laudan: Uma ampla revisão bibliográfica nos principais periódicos brasileiros do ensino de ciências e ensino de física. Investigações em Ensino de Ciências, v. 24, n. 2, p. 38-55, 2019.

BERBEL, N. A. N. As metodologias ativas e a promoção da autonomia de estudantes. Semina: Ciências Sociais e Humanas, v. 32, n. 1, p. 25-40, 2011.

BRASIL. Ministério da Saúde. Secretaria de Vigilância Sanitária. Departamento TécnicoNormativo. Divisão de Meio Ambiente e Ecologia Humana. Organização Pan- Americana de Saúde: Manual de Vigilância da Saúde de Populações Expostas a Agrotóxicos, Brasília, 1997.

BZUNECK, J. A. As crenças de auto-eficácia dos professores. In: SISTO, F.F.; OLIVEIRA, G. de \& FINI, L. D. T. (Org.). Leituras de psicologia para formação de professores. Petrópolis, Rio de Janeiro: Vozes, 2000.

COSTA, L. S. O.; ECHEVERRÍA, A. R.; RIBEIRO, F. L. O Processo de Tomada de Consciência e a Formação de Conceitos da Educação Ambiental na Formação Inicial de Professores de Ciências/ Química. Revista Brasileira de Pesquisa em Educação em Ciências. v. 17, n. 3, p. 803-834, dez, 2017.

DE DAVID, L. síntese do seminário sobre mudanças climáticas desafios da sustentabilidade e da produção de alimentos saudáveis. In: DE DAVID, L. et al. (Org.). Agricultura familiar, produção de alimentos saudáveis e preservação ambiental: relatório verde 2018. Porto Alegre: Assembleia Legislativa do Rio Grande do Sul, 2018. p. 119-134.

DOMIN, D.; BODNER, G. Using Students' Representations Constructed during Problem Solving To Infer Conceptual Understanding. Journal of Chemical Education, n. 89, p. 837-843, 2012.

ECHEVERRÍA, M.D.P.P.; POZO, J.I.; Aprender a resolver problemas e resolver problemas para aprender. In: POZO, J.I.; A solução de problemas. Porto Alegre: Artmed. p. 13-42, 1998.

EHLERS, E. Agricultura sustentável: origens e perspectivas de um novo paradigma. $2^{\mathrm{a}}$ ed., Guaíba: Agropecuária. 157p, 1999.

FAO. Organização das Nações Unidas para a Alimentação e a Agricultura (FAO). Disponível em: <https://nacoesunidas.org/fao-fome-aumenta-no-mundo-e-afeta-821-milhoes-de-pessoas/>. Acesso em: 03 ago. 2019. 
FERNANDES, L. S.; CAMPOS, A. F. Tendências de pesquisa sobre a resolução de problemas em Química. Revista Electrónica de Enseñanza de las Ciencias, v. 16, n. 3, p. 458-482, 2017.

FREIRE, P. Pedagogia da autonomia: saberes necessários à prática educativa. $7^{\mathrm{a}}$ ed. Rio de Janeiro: Paz e Terra, 1998.

FONSECA, M. R. M. Química Ensino Médio. 1ª ed. v. 2. Porto Alegre: Ática, 2013. 320 p.

GIL-PEREZ, D.; MARTINEZ TORREGROSA, J. A model for problem-solving in accordance with scientific methodology. European Journal of Science Education, v. 5, n. 4, p. 447-455, 1983.

GOI, M. E. J.; SANTOS, F. M. T. Formação de professores e o desenvoilvimento de habilidades para a utilização da metodologia de resolução de problemas. Investigações em Ensino de Ciências, v. 19, n. 2, p. 431-450, 2014.

LAUDAN, L. Progress and it's problems. Towards a Theory of Scientific Growth. London: Outledge \& Kegan Pau, 1977. 275 p.

LEWANDOWSKI, I.; HARDTLEIN, M.; KALTSCHMITT, M. Sustainable crop production: definition and methodological approach for assessing and implementing sustainability. Crop Sciences, v. 39, p. 184-193, 1999.

LIMA, F. S. C.; ARENAS, L. T.; PASSOS, C. G. A metodologia de resolução de problemas: uma experiência para o estudo das ligações químicas. Química Nova, v. 41, n. 4, p. 468-475, 2017.

LOUREIRO, C. F. B.; TOZONI-REIS, M. F. C. Teoria social crítica e pedagogia histórico-crítica: contribuições à educação ambiental. Revista Eletrônica do Mestrado em Educação Ambiental, v. 33, p. 68-82, 2016.

LOURENÇO, A. A.; PAIVA, M. O. A motivação escolar e o processo de aprendizagem. Ciências e Cognição, v. 15, n. 2, p. 131-141, 2010.

MARTÍNEZ, F. P.; MARTÍNEZ AZNAR, M. M.; La metodología de resolución de problemas como investigación (MRPI): una propuesta indagativa para desarrollar la competencia científica en alumnos que cursan un programa de diversificación. Enseñanza de las Ciencias, v. 32, n. 3, p. 469- 492, 2014.

MESQUITA, S. A. Avaliação da contaminação do leite materno por pesticidas organoclorados persistentes em mulheres doadoras do banco de leite do Instituto Fernandes Figueira, RJ. 2001. 84 f. Dissertação (Mestrado em Saúde Pública) - Escola Nacional de Saúde Pública, Fundação Oswaldo Cruz, Rio de Janeiro, 2001.

OLIVEIRA, J. E. B. M. A motivação ética no processo de ensino/aprendizagem na formação de professores do ensino fundamental. 2008. 254f Tese (Doutorado em Educação) - Faculdade de Educação, Universidade Federal do Rio de Janeiro, Rio de Janeiro, 2008.

PEREIRA, E. M; CARSON, R. Ciência e Coragem. Ciência Hoje, v. 296, p. 72-73, 2012.

POZO, J.(org.). A Solução de Problemas: Aprender a resolver, resolver para aprender. Porto Alegre: Artmed, 1998.

POZO, J.I. Aprender en tiempos revueltos. La nueva ciencia del aprendizaje. Madrid: Alianza, 2016. POZO, J.I.; CRESPO, M.Á.G. A solução de problemas em ciências da natureza. In: POZO, J.I.; A solução de problemas. Porto Alegre: Artmed, 1998. p. 67-102. 
POZO, J.I.; CRESPO, M. A. G. A aprendizagem e o ensino de ciências: do conhecimento cotidiano ao conhecimento científico. Porto Alegre: Artmed, 2009.

PREISS, P.; VASCONCELLOS, F. C. F.; SCHNEIDER, S. Agricultura e alimentação para o século 21 - novas referências, desafios e perspectivas. In: DE DAVID, L. et al. (Org.). Agricultura familiar, produção de alimentos saudáveis e preservação ambiental: relatório verde 2018. Porto Alegre: Assembleia Legislativa do Rio Grande do Sul, 2018. p. 37-58.

RAMPAZZO, S. E. A questão ambiental no contexto do desenvolvimento econômico. In: BECKER, D. F. (Org.). Desenvolvimento sustentável: necessidade e/ou possibilidade? Santa Cruz do Sul: EDUNISC, 1997. p. 157-188.

RIBEIRO, D. C. A. A temática agrotóxicos e a metodologia da resolução de problemas no ensino de ciências. $1^{a}$ ed. Curitiba: Appris, 2018. 161p.

RIBEIRO, D. C. A.; PASSOS, C. G.; SALGADO, T. D. M. Método de resolução de problemas no ensino médio: uma proposta interdisciplinar abordando o tema agrotóxicos. Revista Prática Docente, v. 3, n. 2, p. 643-664, 2018a.

RIBEIRO, D. C. A.; PASSOS, C. G.; SALGADO, T. D. M. A Resolução de Problemas na Educação Básica: O Processo de Elaboração de Problemas sobre a Temática Ambiental Agrotóxicos. In: EDEQ - ENCONTRO DE DEBATES SOBRE O ENSINO DE QUÍMICA, 38., 2018, Canoas. Anais... Canoas: Ulbra, p. 1- 8, 2018b. Disponível em: <http://edeq.com.br/submissao/index. php/EDEQ/38edeq/paper/view/555/81>. Acesso em: 14 out. 2020.

RIBEIRO, D. C. A.; PASSOS, C. G.; SALGADO, T. D. M. The Environmental Issue of Pesticides: The Problem-Solving Methodology in Elementary School. Acta Scientiae, v. 21, n. 4, p. 97-114, 2019a.

RIBEIRO, D. C. A.; PASSOS, C. G.; SALGADO, T. D. M. A metodologia da resolução de problemas: uma proposta interdisciplinar sobre agrotóxicos na educação de jovens e adultos. Revista Linhas, v. 20 , n. 43 , p. $205-233,2019$ b.

SANTOS, W. L. P.; MÓL, G. S. (org.). Projeto de Ensino de Química e Sociedade: Química cidadã. $2^{2}$ ed. São Paulo: AJS. 320 p, 2013.

SILVA, P. C.; GUIMARÃES, F. L. Controle de Vetores: Procedimentos de Segurança. Brasília: FUNASA, 208 p. , 2010.

SOCKALINGAM, N.; ROTGANS, J. I.; SCHMIDT, H. G. The relationships between problem characteristics, achievement-related behaviors, and academic achievement in problem-based learning. Advances in Health Sciences Education, v. 16, n. 4, p. 481-490, 2011.

SOCKALINGAM, N.; SCHMIDT, H. G. Characteristics of Problems for Problem-Based Learning: The Students' Perspective. Interdisciplinary Journal of Problem-Based Learning, v. 5, n. 1, p. 5-33, 2011.

SOUZA, M. V. Resíduos de Agrotóxicos Ditiocarbamatos e Organofosforados em Alimentos Consumidos no Restaurante Universitário-UNB: Avaliação da Exposição Humana. 2006. 91 f. Dissertação (Mestrado em Ciências da Saúde) - Faculdade de Ciências da Saúde, Universidade de Brasília, Brasília, 2006.

WARTHA, E. J.; SILVA, E. L., BEJARANO, N. R. R. Cotidiano e contextualização no ensino de Química, Química nova na escola, v. 35, n. 2, p. 84-91, maio, 2013.

ZABALA, A. A prática educativa: como ensinar. $1^{a}$ ed. Porto Alegre: Artmed. 224p, 1998. 
Os Autores 2 e 3 supervisionaram o projeto. Todos os autores conceberam a ideia apresentada. Todos os autores desenvolveram a teoria. Os Autores 1 e 2 analisaram os dados e adaptaram os resultados para o enfoque do artigo proposto. Todos os autores discutiram os resultados e contribuíram para a versão final do manuscrito.

\section{NOTAS}

1 O DDT (sigla de diclorodifeniltricloroetano) é o primeiro pesticida moderno, tendo sido largamente usado durante e após a Segunda Guerra Mundial para o combate aos mosquitos vetores de doenças como malária e dengue.

Submetido em 07/07/2020

Aprovado em 14/10/2020

\section{Contato:}

Camila Greff Passos

Instituto de Química da UFRGS

Av. Bento Gonçalves, 9500, prédio 43.111, sala 218-C - Bairro Agronomia

CEP 91.501-970 - Porto Alegre RS - Brasil 